\title{
Dual Antiplatelet or Dual Antithrombotic Therapy for Secondary Prevention in High-Risk Patients with Stable Coronary Artery Disease?
}

\author{
Wael Sumaya ${ }^{1}$ Tobias Geisler ${ }^{2} \quad$ Steen D. Kristensen ${ }^{3}$ Robert F. Storey ${ }^{1}$ \\ ${ }^{1}$ Department of Infection, Immunity and Cardiovascular Disease, \\ University of Sheffield, Sheffield, United Kingdom \\ ${ }^{2}$ Department of Cardiology and Cardiovascular Medicine, University \\ of Tübingen, Tübingen, Germany \\ Address for correspondence Robert F. Storey, BM, DM, FESC, FRCP, \\ Department of Infection, Immunity and Cardiovascular Disease, \\ University of Sheffield, Beech Hill Road, Sheffield, S10 2RX, \\ United Kingdom (e-mail: r.f.storey@sheffield.ac.uk).
}

${ }^{3}$ Department of Cardiology, Aarhus University Hospital, Aarhus, Denmark

Thromb Haemost 2019;119:1583-1589.

\begin{abstract}
Antithrombotic treatment is a key component of secondary prevention following acute coronary syndromes (ACS). Although dual antiplatelet therapy is standard therapy post-ACS, duration of treatment is the subject of ongoing debate. Prolonged dual

Keywords

- coronary artery disease

- dual antiplatelet therapy

- dual antithrombotic therapy

- rivaroxaban

- ticagrelor antiplatelet therapy in high-risk patients with history of myocardial infarction reduced the risk of recurrent myocardial infarction, stroke or cardiovascular death. Similarly, in patients with stable coronary artery disease, two-thirds of whom had a history of myocardial infarction, dual antithrombotic therapy with very-low-dose rivaroxaban and aspirin also resulted in improved ischaemic outcomes. In the absence of head-to-head comparison, choosing the most appropriate treatment strategy can be challenging, particularly when it comes to balancing the risks of ischaemia and bleeding. We aim to review the evidence for currently available antithrombotic treatments and provide a practical algorithm to aid the decision-making process.
\end{abstract}

\section{Introduction}

Dual antiplatelet therapy (DAPT) with aspirin and a P2Y 12 inhibitor forms the backbone of secondary prevention following acute coronary syndromes (ACS). ${ }^{1,2}$ Twelve months' DAPT post-ACS is well established but evidence to support prolonged intensive therapy in high-risk patients following myocardial infarction (MI) continues to emerge. Prolonged ticagrelorbased DAPT reduced recurrent MI, stroke or cardiovascular (CV) death in patients within 1 to 3 years of having an MI in the PEGASUS-TIMI 54 trial. $^{3}$ A meta-analysis that included $>$ 33,000 patients with history of MI from multiple prolonged DAPT trials, including the PEGASUS-TIMI 54 study, also showed prolonged DAPT to result in improved major ischaemic events. ${ }^{4}$ Similarly, in the COMPASS trial, ${ }^{5}$ dual antithrombotic therapy (DATT) with an anticoagulant (very-low-dose rivaroxaban $2.5 \mathrm{mg}$ twice daily) and aspirin resulted in a significant reduction in major $\mathrm{CV}$ events in high-risk stable coronary artery disease (CAD) patients, two-thirds of whom had a history of MI. There was also a numerical reduction in allcause mortality that narrowly missed the pre-specified significance threshold (hazard ratio [HR], 0.82; 95\% confidence interval [CI], 0.71-0.96; $p=0.01$; threshold $p$-value for significance 0.0025). Both treatment strategies resulted in increased risk of major bleeding events and, therefore, the onus is on clinicians to balance the risks of ischaemia and bleeding. Here, we will consider the evidence for and against each of these treatment strategies and provide a practical summary to aid physicians in the decision-making process.

\section{Therapeutic Targets in Arterial Thrombosis}

The role of platelets in arterial thrombosis is well established. As demonstrated in -Fig. 1, at the site of vascular injury, platelets adhere to collagen and von Willebrand factor and these lead to platelet activation. Two key pathways are received

October 11, 2018

accepted after revision January 10, 2019
DOI https://doi.org/

10.1055/s-0039-1679903. ISSN 0340-6245. (c) 2019 Georg Thieme Verlag KG Stuttgart · New York
License terms

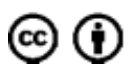




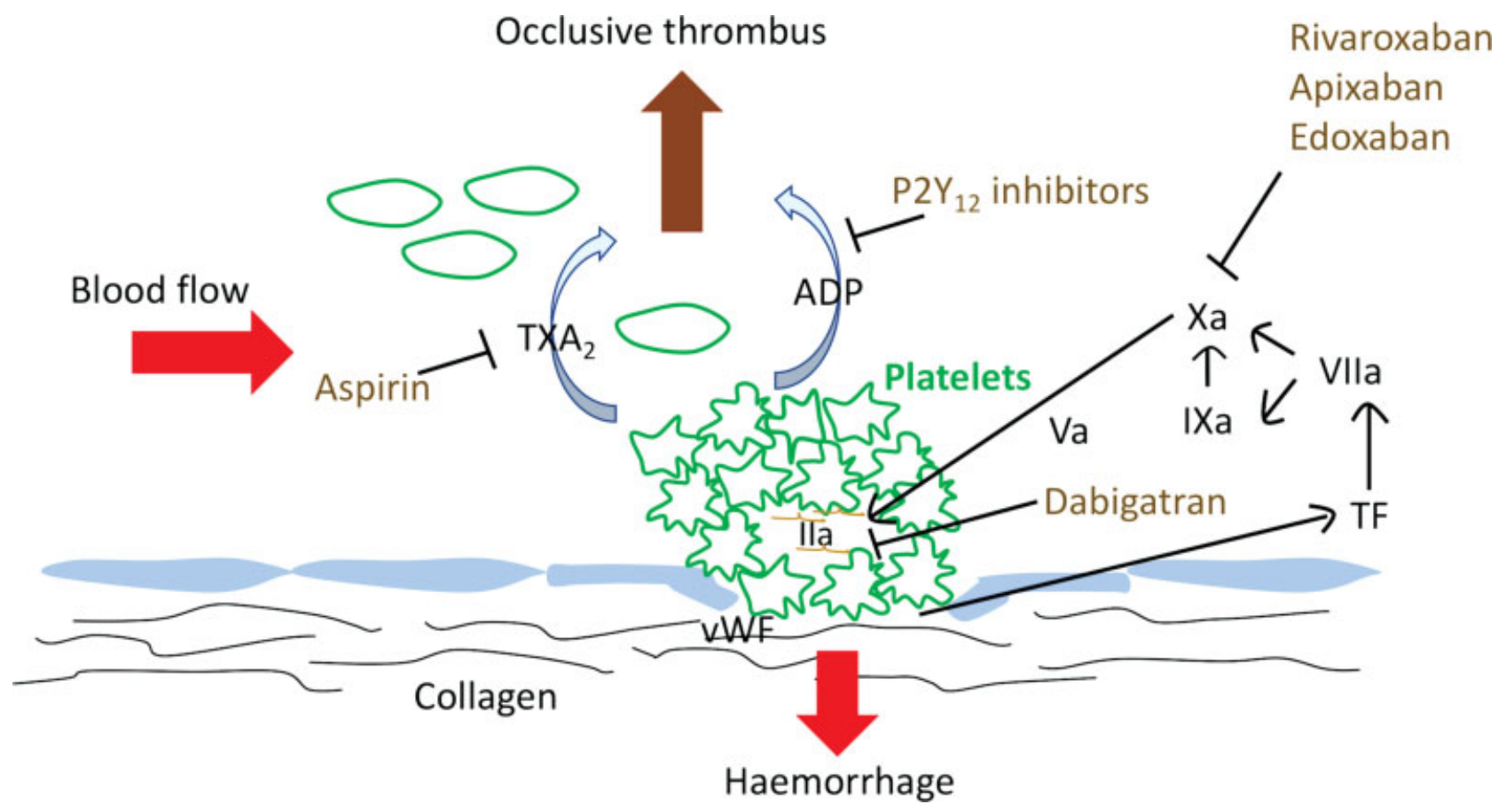

Fig. 1 Arterial thrombosis and modes of action of antithrombotic treatments. Following endothelial disruption, platelets adhere to collagen and von Willebrand factor (VWF) in the sub-endothelial matrix. Activated platelets secrete thromboxane $A_{2}\left(T_{x} A_{2}\right)$, adenosine diphosphate (ADP) and also support the generation of thrombin (Ila). Endothelial disruption and plaque rupture also lead to the expression of tissue factor, triggering the coagulation cascade. Thrombin plays a more important role in stabilizing the core thrombus through fibrin generation in contrast to ADP and $\mathrm{TxA}_{2}$, which play key roles in expansion of the platelet-rich thrombus. ${ }^{40}$ 'a' denotes activated clotting factors.

implicated in amplifying this process, the thromboxane $A_{2}$ $\left(\mathrm{TxA}_{2}\right)$ and the adenosine diphosphate (ADP) $\mathrm{P}_{2} \mathrm{Y}_{12}$ receptor pathways. Cyclooxygenase (COX) 1 is key in the production of $\mathrm{TxA}_{2}$ while ADP is released from platelets' dense granules. ${ }^{6}$ Aspirin targets platelets by irreversible acetylation of COX1 enzyme and currently three oral agents inhibit platelets' $\mathrm{P}_{2} \mathrm{Y}_{12}$ receptors either directly (ticagrelor) or through an active metabolite (clopidogrel and prasugrel). Studies of DAPT have demonstrated the pivotal roles of $\mathrm{TxA}_{2}$ and ADP in coronary thrombosis and, in particular, stent thrombosis. ${ }^{7-9}$

The protein coagulation arm is also activated following vascular injury, leading to thrombin production and consequent fibrin formation. Thrombin also activates platelets through protease-activated receptors (PAR) 1 and $4^{10}$ and so anticoagulants have platelet inhibitory effects through inhibition of thrombin-induced platelet activation, either by directly inhibiting thrombin or by inhibiting thrombin generation. ${ }^{11}$ However, the relative contribution of thrombin to stent thrombosis remains uncertain in comparison to the well-established roles of $\mathrm{TxA}_{2}$ and ADP. Fibrin clots that resist lysis independently predict CV death following ACS, indicating that development of therapies to improve fibrin clot lysis may be a successful avenue in the future. ${ }^{12}$

\section{Oral P2Y 12 Inhibitors}

Multiple landmark clinical trials have established a definitive advantage for combining aspirin and a $\mathrm{P}_{2} \mathrm{Y}_{12}$ inhibitor for approximately 12 months post-ACS. ${ }^{7-9,13}$ Prasugrel and ticagrelor offer more rapid, potent and consistent $\mathrm{P}_{2} \mathrm{Y}_{12}$ inhibi- tion compared with clopidogrel. These properties have translated into improved outcomes. ${ }^{8,9}$ - Table 1 summarizes the pharmacodynamics of each of these agents and provides a summary of appropriate use post-ACS.

\section{Prolonged Dual Antiplatelet Therapy}

Time-limited DAPT assumes that thrombotic risk disappears upon cessation of therapy. However, approximately 1 in 5 patients suffers a major adverse cardiovascular event (MACE) within 3 years after cessation of DAPT. ${ }^{14}$

The CHARISMA trial tested whether clopidogrel-based DAPT would reduce MACE in $>15,000$ patients with multiple atherothrombosis risk factors. ${ }^{15}$ In this study, DAPT did not result in a significant reduction in ischaemic risk; however, only less than $50 \%$ of patients had documented CV disease and, among the third who had history of MI, DAPT appeared to result in improved outcomes. ${ }^{15}$

Similarly, 30 months' DAPT was tested in the DAPT study in patients undergoing percutaneous coronary intervention (PCI), the majority of whom were treated for stable CAD. In this study, prolonged clopidogrel- or prasugrel-based DAPT resulted in a reduction in MI $(2.1 \%$ vs. $4.1 \% ; p<0.001) .^{16}$ Concerns regarding the numerically higher rates of allcause death in the prolonged DAPT group (2\% vs. $1.5 \%$, $p=0.05)$ and the increased risk of major bleeding (2.5\% vs. $1.6 \% ; p=0.001$ ) have limited a general adoption of such a strategy. Patients with MI appeared to accrue the greatest benefit from prolonged DAPT without an increase in allcause death. ${ }^{17}$ 
Table 1 Oral $\mathrm{P}^{2} \mathrm{Y}_{12}$ inhibitors

\begin{tabular}{|c|c|c|}
\hline $\mathrm{P}_{2} \mathrm{Y}_{12}$ inhibitor & Pharmacodynamic properties & Appropriate indications post-ACS \\
\hline Clopidogrel & $\begin{array}{l}\text { Pro-drug; active metabolite irreversibly blocks } \\
\text { platelet P2Y } 12 \text { receptors. Complex pharmacoki- } \\
\text { netics leading to variable pharmacodynamic } \\
\text { response with slow onset and offset of action. }{ }^{34} \\
\text { Genetic variants, drug interactions and unknown } \\
\text { factors lead to poor response in up to } 30 \% \text { of } \\
\text { patients } 35,36\end{array}$ & $\begin{array}{l}\text { 1. When anticoagulation is indicated in addition to } \\
\text { DAPT (e.g. atrial fibrillation, mechanical valves) } \\
\text { 2. In thrombolysis-treated STEMI patients } \\
\text { 3. When the other }{\text { P } 2 Y_{12} \text { inhibitors are either not }} \\
\text { available or contraindicated }\end{array}$ \\
\hline Prasugrel & $\begin{array}{l}\text { Pro-drug; active metabolite irreversibly blocks } \\
\text { platelet } \mathrm{P}_{2} \mathrm{Y}_{12} \text { receptors. Efficient pharmacoki- } \\
\text { netics, starting in the intestines, leading to rapid } \\
\text { platelet inhibition but with similar offset of action } \\
\text { to clopidogrel }\end{array}$ & $\begin{array}{l}\text { 1. Only in PCI-treated ACS patients and either } \\
\text { following angiography or if planned for primary } \\
\mathrm{PCI} \text { in STEMI patients } \\
\text { 2. Should not be used in patients with history of } \\
\text { stroke, cautioned in those } \geq 75 \text { years of age } \\
\text { or }<60 \mathrm{~kg}\end{array}$ \\
\hline Ticagrelor & $\begin{array}{l}\text { Direct-acting drug that reversibly blocks platelet } \\
\mathrm{P}^{2} \mathrm{Y}_{12} \text { receptors. Similar to prasugrel, its onset of } \\
\text { action is rapid, but, being a reversibly binding } \\
{\mathrm{P} 2 \mathrm{Y}_{12} \text { inhibitor, it has more rapid offset of action }}^{38}\end{array}$ & $\begin{array}{l}\text { 1. In patients with NSTEMI and high-risk unstable } \\
\text { angina regardless of treatment strategy. } \\
\text { In STEMI patients planned for primary PCI } \\
\text { 2. Should not be used in patients with history of } \\
\text { intracranial haemorrhage or those taking strong } \\
\text { CYP3A inducers or inhibitors } \\
\text { 3. May be used } 2 \mathrm{~d} \text { post-thrombolysis in STEMI } \\
\text { patients undergoing } \mathrm{PCI}^{39}\end{array}$ \\
\hline
\end{tabular}

Abbreviations: ACS, acute coronary syndrome; DAPT, dual antiplatelet therapy; NSTEMI, non-ST-elevation myocardial infarction; PCI, percutaneous coronary intervention; STEMI, ST-elevation myocardial infarction.

More encouraging results were seen in higher-risk patients in the PEGASUS-TIMI 54 trial. $^{3} \mathrm{~A}$ total of 21,162 patients within 1 to 3 years of having a MI and with additional risk factors (-Table 2) were randomized to placebo, ticagrelor $60 \mathrm{mg}$ twice daily or ticagrelor $90 \mathrm{mg}$ twice daily. Patients with a prior history of stroke or deemed to have high bleeding risk were excluded. Similar to high-dose ticagrelor, ticagrelor $60 \mathrm{mg}$ twice daily reduced the MACE risk compared with placebo (7.77\% vs. $9.04 \%, p<0.001$ ), including a non-significant numerical reduction in $\mathrm{CV}$ mortality in all ticagrelor-treated patients ( $2.9 \%$ vs. $3.39, p=0.06)$, and the similar efficacy of the two doses of ticagrelor was explained by similarly high levels of platelet $\mathrm{P}_{2} \mathrm{Y}_{12}$ inhibition. ${ }^{18}$ Adverse events, primarily dyspnoea and bleeding, were more common with ticagrelor resulting in higher rates of therapy discontinuation, which may have attenuated the benefits observed with ticagrelor. ${ }^{19}$ Very few patients in the trial had been exposed to ticagrelor in the past and better tolerance should be expected if a strategy of continued treatment with aspirin and ticagrelor is adopted in those who have tolerated this combination for the initial 12 months after MI. ${ }^{19}$ Major bleeding was increased with ticagrelor (90 mg: 2.6\%; $60 \mathrm{mg}$ : 2.3\%: placebo: $1.1 \% ; p<0.001$ for each comparison with placebo). It is estimated that 42 MACE would be prevented per year for every 10,000 patients treated with ticagrelor $60 \mathrm{mg}$ at the cost of 31 additional non-fatal major bleeds per year. ${ }^{3}$ Greater absolute risk reductions were seen with ticagrelor in patients with either peripheral artery disease (PAD), chronic kidney disease (CKD) or diabetes mellitus (DM) as well as those with multi-vessel versus single-vessel CAD. ${ }^{20-23}$

A collaborative meta-analysis that included the sub-groups of patients with an index event of MI in thienopyridine-based DAPT studies and patients from the PEGASUS-TIMI 54 study showed that prolonged DAPT reduced MACE (6.4\% vs. $7.5 \%$, $p=0.001)$ and reduced $\mathrm{CV}$ death $(2.3 \%$ vs. $2.6 \%, p=0.03)$ with no significant increase in non-CV death. ${ }^{4}$

Table 2 Key inclusion criteria of PEGASUS-TIMI 54 and COMPASS trials

\begin{tabular}{|l|l|}
\hline Inclusion criteria in the PEGASUS-TIMI 54 trial & Inclusion criteria in the COMPASS trial (CAD cohort $\mathbf{9 0 \% )}$ \\
\hline MI within 1-3 years & MI within 20 years or multi-vessel CAD regardless of previous \\
Age $\geq 50$ years & revascularization \\
One additional risk factor: & Age $\geq 65$ years or PAD or two additional risk factors: \\
Age $\geq 65$ years & Current smoking \\
Diabetes mellitus & Diabetes mellitus \\
PAD & CKD-excluding eGFR $<15 \mathrm{~mL} / \mathrm{min}$ \\
Multi-vessel CAD & Heart failure \\
CKD not requiring dialysis & Non-lacunar ischemic stroke $\geq 1$ month \\
Second previous MI (prior to index MI) & \\
\hline
\end{tabular}

Abbreviations: CAD, coronary artery disease; CKD, chronic kidney disease; eGFR, estimated glomerular filtration rate; MI, myocardial infarction; PAD, peripheral artery disease. 
Based on this evidence, the European Society of Cardiology guidelines give a class IIb recommendation to consider prolonged therapy in ACS patients who have tolerated 12 months of DAPT without bleeding complications. In high-risk patients (such as those identified in the PEGASUS-TIMI 54 trial), prolonged ticagrelor-based DAPT is preferred to thienopyridine-based DAPT. ${ }^{24}$

\section{Anticoagulant Therapy in Secondary Prevention}

The notion of using anticoagulants following ACS for longterm secondary prevention is far from new. Anticoagulation with vitamin $\mathrm{K}$ antagonists (VKAs) following ACS significantly reduced MACE compared with placebo but at the expense of more major bleeding. ${ }^{25}$ However, evidence that DAPT with aspirin and a $\mathrm{P}^{2} \mathrm{Y}_{12}$ inhibitor was markedly superior in the prevention of stent thrombosis to a DATT approach with aspirin and VKA, ${ }^{26,27}$ along with the increasing use of $\mathrm{PCI}$ for the management of ACS, led to preference for a DAPT strategy for ACS management. ${ }^{7}$ Consequently, the combination of aspirin and VKA was relegated to niche indication for ACS patients requiring anticoagulant therapy for other reasons, such as atrial fibrillation.

However, following the development of non-VKA oral anticoagulants, we learned more about the level of anticoagulation that may be needed following ACS in the DAPT era. High anticoagulation levels with apixaban (same levels needed for stroke prevention in AF) in addition to DAPT (aspirin + clopidogrel) resulted in increased risk of major bleeds, including intracranial and fatal bleeds, without a clear benefit of ischaemic risk reduction. ${ }^{28}$

The novel concept of low anticoagulation levels was tested in the ATLAS ACS2-TIMI 51 trial. ${ }^{29}$ Low-dose rivaroxaban (2.5 and $5 \mathrm{mg}$ twice daily), in moderate-to-high-risk ACS patients, in addition to clopidogrel-based DAPT, resulted in a significant reduction in MACE (combined rivaroxaban groups $8.9 \%$ vs. placebo $10.7 \%, p=0.008$ ). This included a reduction in CV death with the lower dose of rivaroxaban ( $2.7 \%$ vs. $4.1 \%$, $p=0.002$ ). The penalty was an increase in non-surgical bleeding (rivaroxaban $2.5 \mathrm{mg} 1.8 \%$ vs. rivaroxaban $5 \mathrm{mg} 2.4 \%$ vs. placebo $0.6 \%, p<0.001$ for each comparison with placebo) and intracranial haemorrhage (rivaroxaban $2.5 \mathrm{mg} 0.4 \%$ vs. rivaroxaban $5 \mathrm{mg} 0.7 \%$ vs. placebo $0.2 \%){ }^{29}$ These results became available at a time when practice favoured one of the more reliable $\mathrm{P}_{2} \mathrm{Y}_{12}$ inhibitors to clopidogrel and this has limited adoption of a triple therapy approach.

The effects of substituting aspirin with rivaroxaban (2.5 mg twice daily) were explored in the GEMINI-ACS-1 study. ${ }^{30}$ Within 10 days of ACS, 3,037 patients were randomized to either rivaroxaban or aspirin in addition to background $\mathrm{P}_{2} \mathrm{Y}_{12}$ inhibitor therapy (clopidogrel or ticagrelor). There was no significant difference in major bleeding between rivaroxaban and aspirin. Exploratory analyses showed a trend for better ischaemic outcomes for those treated with aspirin and ticagrelor compared with other combinations. However, this study was only powered to detect a difference in bleeding endpoints and therefore efficacy outcomes should only be interpreted as hypothesis-generating results.

In the COMPASS trial, ${ }^{5} 27,395$ patients with either stable CAD ( $\sim 90 \%)$ or peripheral artery disease were randomized to standard therapy with aspirin, DATT (aspirin + rivaroxaban $2.5 \mathrm{mg}$ twice daily) or rivaroxaban $5 \mathrm{mg}$ twice daily monotherapy (-Table 2). Patients at high risk for bleeding, including those on DAPT or with coagulopathies, were excluded. DATT resulted in a significant reduction in MACE compared with aspirin ( $4.1 \%$ vs. $5.4 \%$, respectively, $p<0.001$ ), including a reduction in CV death $(1.7 \%$ vs. $2.2 \%, p=0.02)$ and a substantial reduction in ischaemic stroke $(0.7 \%$ vs. $1.4 \%$, $p<0.001)$. There was a penalty of increased major bleeding events with DATT compared with aspirin monotherapy $(3.1 \%$ vs. $1.9 \%, p<0.001)$. However, there was no significant increase in fatal or intracranial haemorrhage. Monotherapy with rivaroxaban $5 \mathrm{mg}$ twice daily did not result in significantly improved ischaemic outcomes but increased major bleeding events.

\section{Choice of Dual Therapy Strategy}

The population studied in the COMPASS trial overlaps substantially with the population studied in the PEGASUS-TIMI 54 trial ( - Tables 2 and 3). All patients in PEGASUS had history of MI (median of 1.7 years prior to randomization) and

Table 3 Baseline patient characteristic in the PEGASUS-TIMI 54 trial and the COMPASS trial

\begin{tabular}{|l|l|l|}
\hline & $\begin{array}{l}\text { The PEGASUS-TIMI } \\
\mathbf{5 4} \text { trial }\end{array}$ & $\begin{array}{l}\text { The COMPASS } \\
\text { trial }\end{array}$ \\
\hline Age (mean \pm SD) & $65 \pm 8$ & $68 \pm 8$ \\
\hline Female & $24 \%$ & $22 \%$ \\
\hline Smoking & $17 \%$ & $21.5 \%$ \\
\hline Hypertension & $78 \%$ & $75 \%$ \\
\hline $\begin{array}{l}\text { Coronary artery } \\
\text { disease }\end{array}$ & $100 \%$ & $90.5 \%$ \\
\hline Previous MI & $100 \%$ & $62 \%$ \\
\hline Years since MI & 1.7 & 7.1 \\
\hline $\begin{array}{l}\text { Peripheral artery } \\
\text { disease }\end{array}$ & $5.5 \%$ & $27.2 \%$ \\
\hline Diabetes mellitus & $32 \%$ & $38 \%$ \\
\hline $\begin{array}{l}\text { Chronic kidney } \\
\text { disease }\end{array}$ & $24 \%$ & $23 \%$ \\
\hline $\begin{array}{l}\text { Previous ischaemic } \\
\text { stroke }\end{array}$ & $0 \%$ & $4 \%$ \\
\hline Prior CABG & $\mathrm{NA}^{\mathrm{a}}$ & $5 \%$ \\
\hline ACE I or ARB & $82 \%$ & $71 \%$ \\
\hline Lipid lowering agent & $93 \%$ & $90 \%$ \\
\hline
\end{tabular}

Abbreviations: ACE I, angiotensin converting enzyme inhibitor; ARB, angiotensin receptor blocker; $C A B G$, coronary artery bypass surgery; $\mathrm{MI}$, myocardial infarction; SD, standard deviation.

${ }^{a}$ In the PEGASUS-TIMI 54 trial, patients who have had bypass surgery were excluded unless they had a myocardial infarction following bypass surgery. 
approximately $60 \%$ of patients in COMPASS had previous MI (average 7.1 years). Both trials show that escalation of antithrombotic therapy in high-risk stable CAD patients leads to improved MACE rates, including numerical reductions in $\mathrm{CV}$ death, particularly in individuals at the highest risk. There is no head-to-head comparison between the two strategies; however, there were signals that prolonged DAPT has greater efficacy at reducing recurrent $\mathrm{MI}$ and stent thrombosis as opposed to greater efficacy for a DATT strategy at reducing stroke. For instance, there was no significant effect of DATT on stent thrombosis rates in COMPASS, whereas prolonged DAPT resulted in a significant reduction in stent thrombosis in the PEGASUS-TIMI 54 trial (ticagrelor $90 \mathrm{mg}$ : HR, 0.30, 95\% CI: 0.14-0.65; ticagrelor $60 \mathrm{mg}$ : HR, 0.66, 95\% CI: 0.37-1.17). ${ }^{31}$ The different mechanisms of action of ticagrelor and rivaroxaban make it credible that ticagrelor would be more effective at preventing occlusive coronary thrombosis, whereas rivaroxaban may be more effective at preventing cardiac thromboem- bolism due to left atrial appendage thrombosis. Although a DATT strategy did not result in overall improved MACE rates in patients with CAD and advanced 'unstable' heart failure, similar signals of efficacy in stroke prevention were observed. $^{32}$ There could also be differential effects of the two drugs on vascular inflammation and progression of atherosclerosis. More research is clearly needed to compare the two strategies, which will help us individualize treatments further.

In the absence of contraindications, ticagrelor is preferred to clopidogrel in ACS patients. ${ }^{24}$ Among high-risk patients who tolerate ticagrelor $90 \mathrm{mg}$ twice daily for a year, it seems appropriate to down-titrate to ticagrelor $60 \mathrm{mg}$ twice daily, in addition to aspirin, for an additional 3 years (or as long as tolerated in the highest-risk patients). In those who have to switch antiplatelet therapy during the first year (e.g. due to dyspnoea) and have completed their intended course of DAPT, starting rivaroxaban $2.5 \mathrm{mg}$ twice daily upon cessation of the $\mathrm{P} \mathrm{Y}_{12}$ inhibitor (after 12 months of DAPT) may be considered.
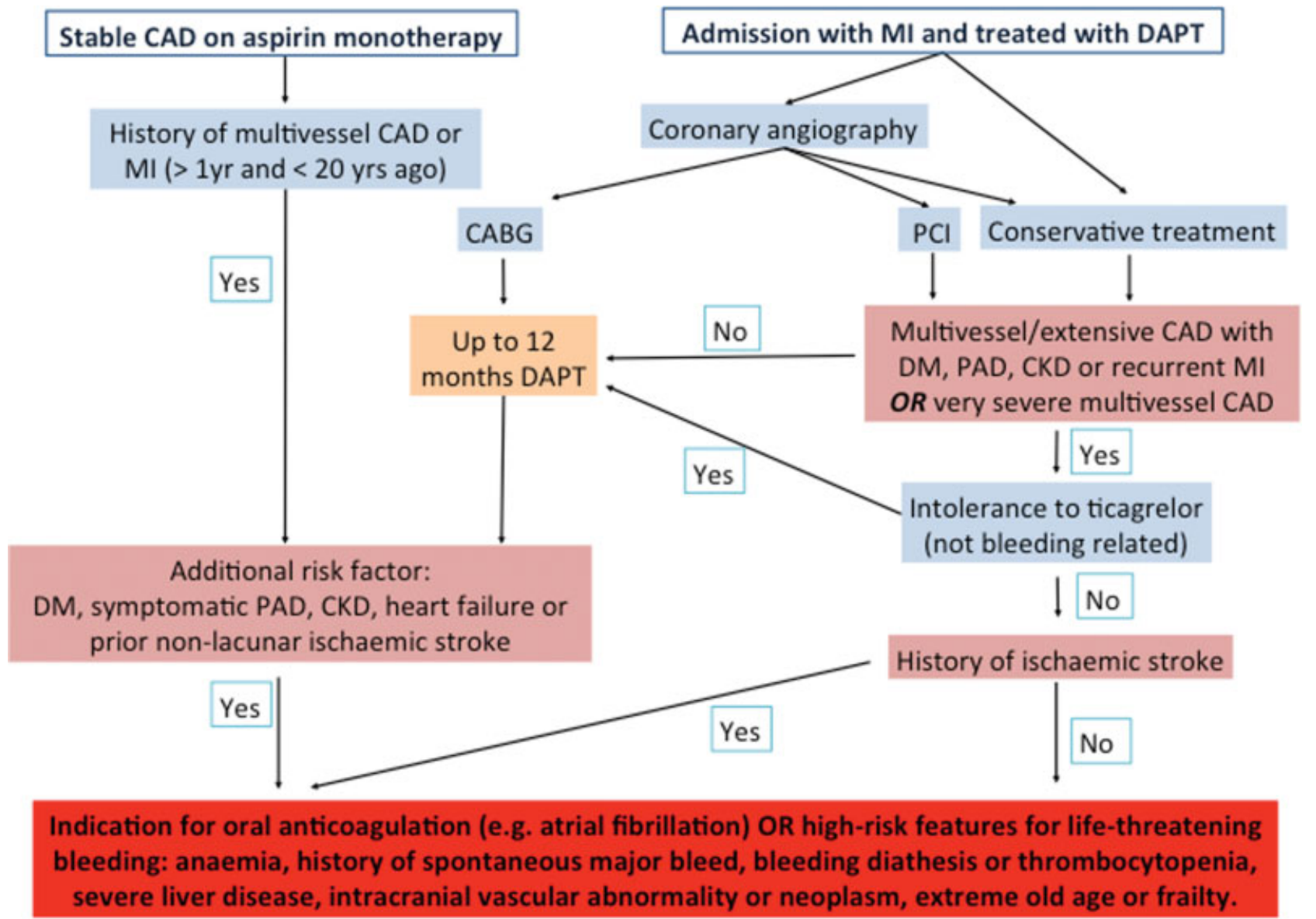

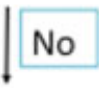

Aspirin + rivaroxaban $2.5 \mathrm{mg} \mathrm{BD}$

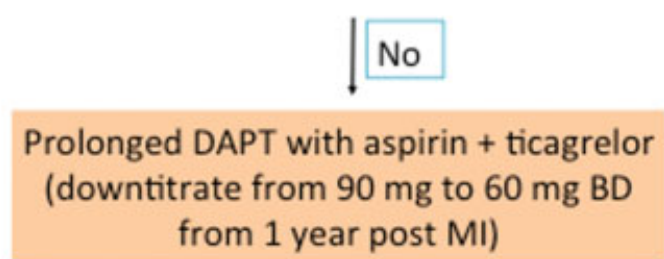

Fig. 2 Choice of antithrombotic treatment strategy in patients with coronary artery disease. CABG, coronary artery bypass surgery; CAD, coronary artery disease; CKD, chronic kidney disease (eGFR $<60 \mathrm{~mL} / \mathrm{min}$ and not requiring dialysis for prolonged DAPT; eGFR $<60 \mathrm{~mL} / \mathrm{min}$ and $>15 \mathrm{~mL} / \mathrm{min}$ for low dose rivaroxaban); DAPT, dual antiplatelet therapy; DATT, dual antithrombotic therapy (aspirin + rivaroxaban $2.5 \mathrm{mg}$ twice daily); DM, diabetes mellitus; PAD, peripheral artery disease; MI: myocardial infarction. 
Treatment decisions are easier to implement at the time of presentation with ACS and become more challenging in those who have been stable on aspirin monotherapy for years. However, when encountering stable high-risk CAD patients (history of ACS with at least two risk factors such as extensive CAD, DM, PAD, CKD or recurrent MI) who are remote from their ACS event ( $>1$ year) and have been stable off DAPT, the addition of rivaroxaban $2.5 \mathrm{mg}$ twice daily may be appropriate. - Fig. 2 provides a decision-making algorithm to aid recommendations for antithrombotic therapy in patients with CAD, particularly those with history of MI.

The risk of bleeding should be balanced against the benefit of ischaemic risk reduction and additional therapy may be best avoided in patients at high risk of life-threatening bleeding. Tools to balance ischaemic and bleeding risk may be useful and the PRECISE-DAPT risk score was developed to aid the decision-making process. ${ }^{33}$ This score, however, has some limitations. It was based on a study of 14,963 patients with CAD who underwent PCI (including elective patients) 33 and identified five predictors of major bleeding events (increasing age, low creatinine clearance, haemoglobin $<10$ $\mathrm{g} / \mathrm{dL}$, increased baseline white cell count and history of spontaneous bleed). Although the derived risk score was validated in two other PCI-treated cohorts, the utility of the score was not studied prospectively. Furthermore, some factors included in the risk score, such as increasing age and CKD (estimated glomerular filtration rate $<60 \mathrm{~mL} / \mathrm{min} /$ $1.73 \mathrm{~m}^{2}$ ), were among the inclusion criteria of both the PEGASUS-TIMI 54 and COMPASS trials and these patients derived benefit from intensive therapy. Patients with anaemia (haemoglobin $<10 \mathrm{~g} / \mathrm{dL}$ ) and those with a history of spontaneous major bleeding were at greatest risk of bleeding and therefore a strategy of prolonged DAPT or DATT is best avoided in these scenarios.

\section{Conclusion}

Protection against atherothrombosis with DAPT, following ACS, is well-established and long-term ticagrelor-based DAPT, in high-risk stable patients with history of MI, has demonstrated further benefit. Consequently, prolonged DAPT may be considered in high-risk post-MI patients, with stronger consideration given to those who are at high risk of CAD-related death (e.g. extensive multi-vessel CAD) but deemed at low risk for fatal bleeding (i.e. no history of intracranial haemorrhage, stroke, bleeding diathesis or incurable gastrointestinal bleeding). The COMPASS study results provide support for the use of DATT (aspirin + rivaroxaban $2.5 \mathrm{mg}$ twice daily) in stable patients with history of MI, PAD and/or multiple risk factors. Among high-risk stable patients who are not taking DAPT, DATT may be considered to reduce the risk of further ischaemic events, again with stronger consideration given to those who are at high risk of CV death and low risk of fatal bleeding.

\section{Conflict of Interest}

W.S.: Speaker fees from Bayer. T.G.: Speaker fees from AstraZeneca, Bayer AG, Bristol Myers Squibb/Pfizer, Daii- chi Sankyo and Boehringer Ingelheim. Research grants from Bayer AG, Bristol Myers Squibb/Pfizer and Daiichi Sankyo. S.D.K.: Speaker fees from AstraZeneca, Bayer AG and Bristol Myers Squibb/Pfizer. R.F.S.: Research grants from AstraZeneca and PlaqueTec. Honoraria from AstraZeneca and Bayer. Consultancy fees from AstraZeneca, Actelion, Avacta, Bayer, Bristol Myers Squibb/Pfizer, Haemonetics, Idorsia, Novartis, PlaqueTec and Thromboserin.

\section{Funding}

W.S. was funded by British Heart Foundation Clinical Research Training Fellowship (FS/15/82/31824).

\section{References}

1 Roffi M, Patrono C, Collet JP, et al; ESC Scientific Document Group. 2015 ESC Guidelines for the management of acute coronary syndromes in patients presenting without persistent ST-segment elevation: Task Force for the Management of Acute Coronary Syndromes in Patients Presenting without Persistent ST-Segment Elevation of the European Society of Cardiology (ESC). Eur Heart J 2016;37(03):267-315

2 Ibanez B, James S, Agewall S, et al; ESC Scientific Document Group. 2017 ESC Guidelines for the management of acute myocardial infarction in patients presenting with ST-segment elevation: the Task Force for the management of acute myocardial infarction in patients presenting with ST-segment elevation of the European Society of Cardiology (ESC). Eur Heart J 2018;39(02):119-177

3 Bonaca MP, Bhatt DL, Cohen M, et al; PEGASUS-TIMI 54 Steering Committee and Investigators. Long-term use of ticagrelor in patients with prior myocardial infarction. N Engl J Med 2015; 372(19):1791-1800

4 Udell JA, Bonaca MP, Collet JP, et al. Long-term dual antiplatelet therapy for secondary prevention of cardiovascular events in the subgroup of patients with previous myocardial infarction: a collaborative meta-analysis of randomized trials. Eur Heart J 2016;37(04):390-399

5 Eikelboom JW, Connolly SJ, Bosch J, et al; COMPASS Investigators. Rivaroxaban with or without aspirin in stable cardiovascular disease. N Engl J Med 2017;377(14):1319-1330

6 Storey RF. Biology and pharmacology of the platelet $\mathrm{P}_{2} \mathrm{Y}_{12}$ receptor. Curr Pharm Des 2006;12(10):1255-1259

7 Yusuf S, Zhao F, Mehta SR, Chrolavicius S, Tognoni G, Fox KK; Clopidogrel in Unstable Angina to Prevent Recurrent Events Trial Investigators. Effects of clopidogrel in addition to aspirin in patients with acute coronary syndromes without ST-segment elevation. N Engl J Med 2001;345(07):494-502

8 Wiviott SD, Braunwald E, McCabe $\mathrm{CH}$, et al; TRITON-TIMI 38 Investigators. Prasugrel versus clopidogrel in patients with acute coronary syndromes. N Engl J Med 2007;357(20):2001-2015

9 Wallentin L, Becker RC, Budaj A, et al; PLATO Investigators. Ticagrelor versus clopidogrel in patients with acute coronary syndromes. N Engl J Med 2009;361(11):1045-1057

10 Borst $\mathrm{O}$, Münzer $\mathrm{P}$, Alnaggar $\mathrm{N}$, et al. Inhibitory mechanisms of very low-dose rivaroxaban in non-ST-elevation myocardial infarction. Blood Adv 2018;2(06):715-730

11 Sumaya W, Parker WAE, Fretwell R, et al. Pharmacodynamic effects of a 6-hour regimen of enoxaparin in patients undergoing primary percutaneous coronary intervention (PENNY PCI Study). Thromb Haemost 2018;118(07):1250-1256

12 Sumaya W, Wallentin L, James SK, et al. Fibrin clot properties independently predict adverse clinical outcome following acute coronary syndrome: a PLATO substudy. Eur Heart J 2018;39(13): 1078-1085

13 Roe MT, Armstrong PW, Fox KA, et al; TRILOGY ACS Investigators. Prasugrel versus clopidogrel for acute coronary syndromes 
without revascularization. N Engl J Med 2012;367(14): 1297-1309

14 Jernberg T, Hasvold P, Henriksson M, Hjelm H, Thuresson M, Janzon M. Cardiovascular risk in post-myocardial infarction patients: nationwide real world data demonstrate the importance of a long-term perspective. Eur Heart J 2015;36(19): $1163-1170$

15 Bhatt DL, Fox KA, Hacke W, et al; CHARISMA Investigators. Clopidogrel and aspirin versus aspirin alone for the prevention of atherothrombotic events. N Engl J Med 2006;354(16):1706-1717

16 Mauri L, Kereiakes DJ, Yeh RW, et al; DAPT Study Investigators. Twelve or 30 months of dual antiplatelet therapy after drugeluting stents. N Engl J Med 2014;371(23):2155-2166

17 Yeh RW, Kereiakes DJ, Steg PG, et al; DAPT Study Investigators. Benefits and risks of extended duration dual antiplatelet therapy after $\mathrm{PCI}$ in patients with and without acute myocardial infarction. J Am Coll Cardiol 2015;65(20):2211-2221

18 Storey RF, Angiolillo DJ, Bonaca MP, et al. Platelet inhibition with ticagrelor $60 \mathrm{mg}$ versus $90 \mathrm{mg}$ twice daily in the PEGASUS-TIMI 54 trial. J Am Coll Cardiol 2016;67(10):1145-1154

19 Bonaca MP, Bhatt DL, Oude Ophuis T, et al. Long-term tolerability of ticagrelor for the secondary prevention of major adverse cardiovascular events: a secondary analysis of the PEGASUSTIMI 54 trial. JAMA Cardiol 2016;1(04):425-432

20 Bonaca MP, Bhatt DL, Storey RF, et al. Ticagrelor for prevention of ischemic events after myocardial infarction in patients with peripheral artery disease. J Am Coll Cardiol 2016;67(23):2719-2728

21 Magnani G, Storey RF, Steg G, et al. Efficacy and safety of ticagrelor for long-term secondary prevention of atherothrombotic events in relation to renal function: insights from the PEGASUS-TIMI 54 trial. Eur Heart J 2016;37(04):400-408

22 Bhatt DL, Bonaca MP, Bansilal S, et al. Reduction in ischemic events with ticagrelor in diabetic patients with prior myocardial infarction in PEGASUS-TIMI 54. J Am Coll Cardiol 2016;67(23): 2732-2740

23 Bansilal S, Bonaca MP, Cornel JH, et al. Ticagrelor for secondary prevention of atherothrombotic events in patients with multivessel coronary disease. J Am Coll Cardiol 2018;71(05):489-496

24 Valgimigli M, Bueno H, Byrne RA, et al; ESC Scientific Document Group; ESC Committee for Practice Guidelines (CPG); ESC National Cardiac Societies. 2017 ESC focused update on dual antiplatelet therapy in coronary artery disease developed in collaboration with EACTS: the Task Force for dual antiplatelet therapy in coronary artery disease of the European Society of Cardiology (ESC) and of the European Association for CardioThoracic Surgery (EACTS). Eur Heart J 2018;39(03):213-260

25 Smith P, Arnesen H, Holme I. The effect of warfarin on mortality and reinfarction after myocardial infarction. N Engl J Med 1990; 323(03):147-152

26 Schömig A, Neumann FJ, Kastrati A, et al. A randomized comparison of antiplatelet and anticoagulant therapy after the placement of coronary-artery stents. N Engl J Med 1996;334(17): 1084-1089
27 Leon MB, Baim DS, Popma JJ, et al; Stent Anticoagulation Restenosis Study Investigators. A clinical trial comparing three antithrombotic-drug regimens after coronary-artery stenting. N Engl J Med 1998;339(23):1665-1671

28 Alexander JH, Lopes RD, James S, et al; APPRAISE-2 Investigators. Apixaban with antiplatelet therapy after acute coronary syndrome. N Engl J Med 2011;365(08):699-708

29 Mega JL, Braunwald E, Wiviott SD, et al; ATLAS ACS 2-TIMI 51 Investigators. Rivaroxaban in patients with a recent acute coronary syndrome. N Engl J Med 2012;366(01):9-19

30 Ohman EM, Roe MT, Steg PG, et al. Clinically significant bleeding with low-dose rivaroxaban versus aspirin, in addition to P2Y12 inhibition, in acute coronary syndromes (GEMINI-ACS-1): a double-blind, multicentre, randomised trial. Lancet 2017;389(10081):1799-1808

31 Bonaca MP, Bhatt DL, Steg G, et al. Efficacy of long-term ticagrelor in stented patients in PEGASUS-TIMI 54. J Am Coll Cardiol 2015;66(Suppl B):B36

32 Zannad F, Anker SD, Byra WM, et al; COMMANDER HF Investigators. Rivaroxaban in patients with heart failure, sinus rhythm, and coronary disease. N Engl J Med 2018;379(14):1332-1342

33 Costa F, van Klaveren D, James S, et al; PRECISE-DAPT Study Investigators. Derivation and validation of the predicting bleeding complications in patients undergoing stent implantation and subsequent dual antiplatelet therapy (PRECISE-DAPT) score: a pooled analysis of individual-patient datasets from clinical trials. Lancet 2017;389(10073):1025-1034

34 Caplain H, Donat F, Gaud C, Necciari J. Pharmacokinetics of clopidogrel. Semin Thromb Hemost 1999;25(Suppl 2):25-28

35 Stone GW, Witzenbichler B, Weisz G, et al; ADAPT-DES Investigators. Platelet reactivity and clinical outcomes after coronary artery implantation of drug-eluting stents (ADAPT-DES): a prospective multicentre registry study. Lancet 2013;382(9892):614-623

36 Orme RC, Parker WAE, Thomas MR, et al. Study of two dose regimens of ticagrelor compared with clopidogrel in patients undergoing percutaneous coronary intervention for stable coronary artery disease (STEEL-PCI). Circulation 2018. Doi: CIRCULATIONAHA.118.034790

37 Payne CD, Li YG, Small DS, et al. Increased active metabolite formation explains the greater platelet inhibition with prasugrel compared to high-dose clopidogrel. J Cardiovasc Pharmacol 2007; 50(05):555-562

38 Gurbel PA, Bliden KP, Butler K, et al. Randomized double-blind assessment of the ONSET and OFFSET of the antiplatelet effects of ticagrelor versus clopidogrel in patients with stable coronary artery disease: the ONSET/OFFSET study. Circulation 2009;120 (25):2577-2585

39 Berwanger O, Nicolau JC, Carvalho AC, et al; TREAT Study Group. Ticagrelor vs clopidogrel after fibrinolytic therapy in patients with ST-elevation myocardial infarction: a randomized clinical trial. JAMA Cardiol 2018;3(05):391-399

40 Welsh JD, Stalker TJ, Voronov R, et al. A systems approach to hemostasis: 1 . The interdependence of thrombus architecture and agonist movements in the gaps between platelets. Blood 2014;124(11):1808-1815 